\title{
Construcción estatal, orden oligárquico y respuestas sociales: Argentina y Chile, 1840-1930 Ernesto Bohoslavsky y Milton Godoy Orellana (editores)
}

Prometeo Libros. Los Polvorines: Universidad Nacional de General Sarmiento. Buenos Aires, 2010, 336 páginas.

\section{Jorge Gaete Lagos}

Universidad Nacional Andrés Bello, Santiago, Chile. Email: jlgaete_reload@hotmail.com

Frecuentemente, los historiadores sitúan sus investigaciones en torno a una serie de límites, tales como un cierto número de años, algún período histórico en particular, las fronteras naturales de una comuna, provincia, región, o país, entre muchos otros. Esta técnica se usa con el objeto de abordar y profundizar de mayor y mejor manera los temas que en los trabajos se recogen, lo que provoca que todo lo que queda fuera del tema estudiado se deje de lado, o se mencione de manera mínima en algunos marcos conceptuales o pies de página.

Es este elemento lo que le otorga al presente libro un estilo propio y un cierto grado de osadía, debido a que sus autores buscan ir más allá de estas "fronteras" temáticas, al plantearse analizar los procesos de construcción de Estado en Argentina y Chile entre los años 1840 y 1930, las diferencias y similitudes entre ambos países, y los conflictos y resistencias sociales que hubo en conjunto a este proceso, lo que representa un notable esfuerzo en abordar una línea de trabajo que ha sido muy poco profundizada. En esta serie de artículos, y tal como lo señala el prólogo de Antonio Elizalde, se le da un particular énfasis al accionar del Estado y a los sujetos históricos invisibles, los que a lo largo de estas páginas se van haciendo visibles.

Los artículos que conforman la primera sección de este texto, abordan el actuar que tuvieron las instituciones durante el siglo XIX, y los límites que poseían. En los tres escritos, los autores logran mostrar de muy buena manera el difícil camino que ambos Estados tuvieron para cohesionar y controlar a estas sociedades en torno a lo que dispusieron como objetivos.

En el primero de estos trabajos, Mauricio Rojas se centra en la Provincia de Concepción, con el propósito de analizar la lucha que organismos como el Estado y la Iglesia sostuvieron contra prácticas arraigadas como el 
amancebamiento y la bigamia, lo que desarrolla gracias al uso que hace del expediente en el que el gobernador del obispado de Concepción José Estuardo acusa muchas veces a Manuel Cordero por vivir en concubinato con un par de mujeres, polemizando con el Estado por su lento accionar en ese tipo de situaciones que provocaban "pánico moral”. A partir de este caso, y utilizando como referencias secundarias algunas fuentes bibliográficas y documentales, Rojas señala la debilidad que tuvo la respuesta tanto de Cordero como de otras personas que se negaban a seguir las normas impuestas por el Estado y por la Iglesia, y a su vez muestra el complejo proceso de secularización, las pugnas que hubo entre autoridades eclesiásticas y estatales para controlar este tipo de prácticas, y los posteriores cambios legislativos que se desarrollaron.

La poderosa influencia que buscó tener el Estado es un tema que también se aborda, para el caso argentino, en el segundo y tercer trabajo de este apartado. Por un lado, Roberto Schmit y Andrés Cuello estudian las transformaciones que hubo en la provincia argentina de Entre Ríos entre 1850 y 1880, y se enfocan en el control que el Estado buscó tener sobre los derechos de propiedad y los suelos para sus propios fines. Ambos destacan que si bien los habitantes que había en la provincia eran ocupantes, arrendatarios y propietarios, la guerra civil y la batalla de Pavón le provocaron la necesidad al Estado de regularizar de mejor manera esta situación, y de contar con mayores recursos en sus arcas fiscales, traduciéndose esto en la promulgación de leyes de arrendamiento y venta de tierras públicas en 1860 y 1861 respectivamente y en cambios profundos en el seno de la sociedad entrerriana, como la posterior proletarización que enfrentaron las personas de menores recursos.

A su vez, Gabriel Carrizo nos habla de la dura realidad existente en la zona patagónica de Chubut entre 1887 y 1930. Destaca la inseguridad de la región y la incapacidad del Estado para establecerse de manera eficaz a través de su policía, a pesar de la creación de organismos como los Yacimientos Petrolíferos Fiscales (YPF), y de la gestión del comisario Vicente Cambeiro, los cuales buscaron aumentar la cantidad de funcionarios y hacer más eficiente la gestión tanto en la frontera con Chile como en la pampa. Esta compleja situación se tradujo en la difícil creación de autoridad, en la búsqueda forzosa de disciplina, y en las tensiones entre policías, bandoleros y pobladores.

En la segunda parte del libro, los trabajos abordan las respuestas y resistencias populares que hubo frente a las medidas que implementaron los Estados de Chile y Argentina. Es acá donde el libro logra demostrar la debilidad que ambos tuvieron y el esfuerzo que tuvieron que realizar frente a prácticas y actitudes tan arraigadas en la gente, lo que permite mostrar una vez más, sobre todo para el caso chileno, que la construcción del Estado fue un proceso que se logró consolidar luego de muchas décadas de conflictos populares, derribando la vieja tesis sobre la tranquilidad del mismo. 
En su artículo, el historiador chileno Milton Godoy habla del carnaval, del discurso cultural, y las reacciones que tuvieron los habitantes del norte chico ante las medidas que dispuso por el Estado chileno para combatir los perjuicios que provocaban estas prácticas, entre los años 1840 y 1900. Junto con mostrar la necesidad existente en la época de "ordenar lo festivo", Godoy muestra la reticencia que esto tuvo, los excesos en fiestas religiosas como la Challa y las mofas hacia las autoridades, por lo que se hizo necesario tomar medidas radicales y modificar el ethos de la sociedad. Indica que estas disposiciones y el avance de la urbanización provocaron un repliegue del carnaval, desapareciendo este con la llegada del siglo XX

Posteriormente, nos encontramos con tres artículos que se centran en la zona en la frontera mapuche y en el accionar del Estado luego de su llegada a la zona. En el primero de ellos, Hugo Contreras y Manuel Fernández abordan lo ocurrido en la Alta Frontera, específicamente en la ciudad de Los Ángeles y sus alrededores entre 1860 y 1875. Ambos autores analizan el lento proceso de incorporación de los angelinos al Estado chileno, el que se vio interrumpido constantemente por la presencia de asaltantes, por vicios como el alcohol y la desenfrenada la diversión popular, por la falta de educación de los habitantes del lugar, y por el escaso presupuesto invertido por el Estado para regular estas situaciones. Sin embargo, logran exponer que a finales del siglo XIX los angelinos parecían acceder a lo que el Estado les ofrecía para surgir, ya que un grupo de adultos solicitó la construcción de una escuela para ellos.

Por su parte, Rodrigo Araya indica las mismas dificultades que hubo en la ciudad de Valdivia, entre los años 1871 y 1884, aunque pone su atención en la criminalidad y el control social. Araya muestra que con el paso del tiempo, y con la llegada de los alemanes, la ciudad surgió a través de la agroindustria, y por los inmigrantes alemanes, los cuales fueron pacíficos a diferencia de las autoridades chilenas, pero aún así muestra que hubo delitos, hurtos, e incluso asesinatos, provocados por los ladrones atraídos por la riqueza y por la inexistencia de una policía rural eficiente. Esta violencia hacia la autoridad también se señala en el artículo de Leonardo León, el cual estudia el bandidaje rural en la Araucanía en el período 1880 y 1900, en el que destaca la enorme ferocidad con la que atacaron los bandoleros a las personas y a todo lo que tuviera que ver con civilización, lo que le trajo más de un dolor de cabeza a las autoridades de la época.

En la última sección del libro, los trabajos muestran la construcción de clase y ciudadanía que hubo en ambos países, apegándose a lo político por sobre lo social, lo que sigue la verdadera etimología de "ciudadano". En el primero de los trabajos, Daniel Palma analiza los motines ocurridos en 1851, enfatizando en las formas que hubo de movilización y en los hechos que sucedieron en las zonas de San Felipe, Santiago, Valparaíso y Chañarcillo. A pesar de que por un lado señala que las demandas de los habitantes de esta zona eran una crítica a situaciones como el centralismo y el desempleo, y por otro desmitifica lo ocurrido con la Sociedad de la Igualdad en Santiago a mediados de esta centuria, lo que no pasó de ser una 
alteración al orden público, Palma consigue exponer las maneras que tuvieron los habitantes de estos lugares para organizarse, trayendo como consecuencia la reacción de las autoridades de resguardar el orden público para evitar hechos de violencia.

Luego de esto, Ernesto Bohoslawsky nos muestra la organización que tuvieron los habitantes de la Patagonia chilena y argentina frente a los sectores capitalistas. Señala que los obreros se organizaron en las Federaciones Obreras de Magallanes (FOM) y de Santa Cruz, radicalizándose las manifestaciones de los carniceros y de los frigoríficos en Punta Arenas, aunque fueron duramente reprimidos.

En el último artículo del libro, Lisandro Gallucci se centra en la construcción de la ciudadanía en la zona patagónica de Neuquén durante las primeras décadas del siglo XX. Aquí pone énfasis en que los habitantes de la zona gozaron de libertades políticas, aunque estaban limitadas a causa de la lejanía del territorio y por las medidas que implementó el Estado para evitar el surgimiento de caudillos locales, lo que se tradujo en que ellos accedieron solo al voto municipal, y en la consolidación de una elite regional al mando de los altos cargos. A su vez, Gallucci muestra las malas prácticas que los partidos de la zona tuvieron para conseguir votantes, como el clientelismo y el acarreo de votos, lo que produjo irregularidades y críticas a Buenos Aires por el abandono que sufrían.

No cabe duda que, tal como lo indica Germán Soprano en el epílogo, este libro contribuye a comparar lo ocurrido en ambos países, a mostrar los aportes de los actores institucionales estatales y sociales, y a intercambiar información entre estas naciones del cono sur. Además, Soprano realiza excelentes críticas, entre las cuales señala que se debe especificar en lo particular, en lo que la sociedad de un país mantiene y transa luego de lo implementado por su Estado, en los grupos medios, y en el estudio y sociología del aparato estatal.

En consecuencia, y aunque constituye un primer gran esfuerzo, el presente texto se hace muy recomendable para incentivar a que futuras investigaciones ahonden en esta línea de trabajo. Es de esperar que esto ocurra, ya que permitirá construir una futura y renovada historia contemporánea de América del Sur, mucho más completa que las que existen en la actualidad.

Recibido: 11.04.2012

Aceptado: 25.07.2012 